Evaluación del efecto anti-Trypanosoma cruzi del aceite esencial de Thymus vulgaris L (tomillo) y su principal componente, timol, en ratones

Juan Rojas, Olga Palacios

Facultad de Medicina, UNMSM

Objetivos: Determinar el efecto anti-Trypanosoma cruzi del aceite esencial de Thymus vulgaris y del timol, en ratones. Diseño: Estudio experimental in vivo, prospectivo, de corte longitudinal.

Institución: Facultad de Medicina, UNMSM.

Material biológico: Ratones albinos.

Intervenciones: Se utilizó ratones albinos que fueron asignados aleatoriamente a los siguientes grupos $(n=15)$ : infectados y no tratados (G1), infectados y tratados con aceite esencial de Thymus vulgaris $200 \mathrm{mg} / \mathrm{kg}$ (G2), infectados y tratados con timol $200 \mathrm{mg} / \mathrm{kg}$ (G3), infectados y tratados con benznidazol $100 \mathrm{mg} / \mathrm{kg}$ (G4), no infectados y no tratados (G5), y no infectados y tratados con $200 \mathrm{mg} / \mathrm{kg}$ de Thymus vulgaris (G6).

Principales medidas de resultados: Parasitemia, estudio histopatológico.

Resultados: Al final del experimento, el aceite esencial de Thymus vulgaris y el timol redujeron significativamente el número de tripomastigotes en el pico de la parasitemia, así como el número de amastigotes y de infiltrados inflamatorios en tejido cardiaco.

Conclusiones: El aceite esencial de Thymus vulgaris y el timol tuvieron efecto anti-Trypanosoma cruzi in vivo, en ratones.

Palabras clave: Trypanosoma cruzi, aceite esencial, Thymus vulgaris, timol, tomillo.

\title{
Evaluación del cocimiento de diferentes biovariedades de Caesalpinia spinosa (tara) frente a cepas de Staphylococcus aureus sensibles y resistentes a oxacilina
}

José Guevara G., Juan Guevara G., José Guevara D., Vilma Béjar, Ana Huamán, Esther Valencia, Patricia Abanto

Instituto de Medicina Tropical Daniel A. Carrión, Facultad de Medicina, UNMSM

Objetivos: Comprobar la actividad antimicrobiana de tres biovariedades de tara frente a cepas de Staphylococcus aureus sensibles y resistentes a oxacilina.

Diseño: Es un estudio descriptivo prospectivo analítico.

Institución: Instituto de Medicina Tropical Daniel A. Carrión, Facultad de Medicina, UNMSM.

Material biológico: Se evaluó 31 cepas S. aureus oxacilina sensibles y 29 resistentes, aisladas de muestras clínicas, frente a tres cocimientos de tara de las zonas de Huamanga, Huarochiri y Tarma.

Intervenciones: Se preparó el cocimiento de tara y se impregnó discos en blanco para utilizarlos como un antibiograma por disco difusión.

Principales medidas de resultados: Diámetro de los halos de inhibición.

Resultados: Los tres cocimientos presentaron actividad antimicrobiana frente a las cepas de Staphylococcus aureus; el cocimiento de Huamanga tuvo mayor halo de inhibición frente a cepas sensibles y resistentes. El cocimiento de Huarochirí mostró mayor halo de inhibición en cepas oxacilino resistentes que las sensibles; la diferencia fue significativa. El cocimiento de Huarochiri presentó una actividad menor y significativa frente a los cocimientos de Huamanga y Tarma.

Conclusiones: El cocimiento de Huarochirí presentó menor actividad que los de Huamanga y Tarma.

Palabras clave: Cocimiento, tara, Huamanga, Tarma, Huarochirí, Staphylococcus aureus. 